\title{
Serotyping and adaptation of foot and mouth disease virus in BHK-2I cell line towards the development of vaccine candidate
}

\begin{abstract}
This research work was conducted for isolation, identification and serotyping of Foot and Mouth Disease (FMD) virus from the field isolates of Gouripur Upazila of Mymensingh district, Bangladesh. Samples were collected from infected cattle in virus transportation medium and transported at the Department of Microbiology and Hygiene, Bangladesh Agricultural University, Mymensingh with maintain proper cool chain during October to April 2012. Inocula were prepared from the collected samples and treated with antibioticsantimycotics, preserved at $-20^{\circ} \mathrm{C}$ for isolation and serotyping of the virus by antigen detecting ELISA method. After serotyping, the prepared inoculum was inoculated into 24hours confluent BHK-21 cell culture separately and incubated at $37^{\circ} \mathrm{C}$ for 48 hours for development of CPE. Within 48hours of post infection, complete development of cytopathic effects (CPE) in BHK-21 cell culture were observed under inverted microscope which included the rounding and flattening of the cells, breaking down of the intracellular bridges and finally cell death which indicated the presence of FMD virus. Clear BHK21 cell culture fluid was collected and preserved at $-80^{\circ} \mathrm{C}$ as seed. Of the 20 samples, $15(75 \%)$ samples were found positive for FMDV in cell culture of which 13 samples of tongue epithelia $(86.67 \%)$ and 2 samples of foot tissues $(40 \%)$ were positive on the basis of cytopathic effects (CPE). Again the prepared inoculum was taken for serotyping the virus by ELISA method. On the basis of the result of ELISA, it was concluded that the serotype of the FMD virus of the collected field isolate was serotype "O".
\end{abstract}

Keywords: FMDV, BHK-21, CPE, ELISA, serotyping, cytopathic, inoculum, antimycotics, antibiotics
Volume 3 Issue 2 - 2016

\author{
Shahiduzzaman ANM,' Haque ME, ${ }^{1,2}$ Rahman \\ $M H,{ }^{1,3}$ Khan MFR,' Rahman MB' \\ 'Department of Microbiology and Hygiene, Bangladesh \\ Agricultural University, Bangladesh \\ 2Department of Biochemistry and cell biology, Kyungpook \\ National University, South Korea \\ ${ }^{3}$ Bangladesh Livestock Research Institute, Bangladesh
}

Correspondence: Md Bahanur Rahman, Department of Microbiology and Hygiene, Bangladesh Agricultural University, Mymensingh, Bangladesh, Tel +88(0)916740I-6, Email bahanurr@gmail.com

Received: October 31, 2016 | Published: December 09, 2016
Abbreviations: FMDV, foot and mouth disease virus; BHK, baby hamster kidney; CPE, cytopathic effects; ELISA, enzyme linked immunosorbent assay; FMD, foot and mouth disease; CFT, complement fixation test, VNT, virus neutralization test; PBS, phosphate buffered saline; IF, infectious fluids; OD, optical density; BA, bacteriological media; ELISA, enzyme linked immunosorbent assay

\section{Introduction}

Foot and mouth disease (FMD), usually called Apthus fever, is an acute, febrile, highly contagious and sometimes fatal viral disease of almost all the cloven-hoofed domestic animals, cattle, buffalo, sheep, goat and swine. The foot and mouth disease virus (FMDV) also affects more than 70 species of wild animals including deer, antilope etc. ${ }^{1}$ This virus belongs to the genus Aphthovirusunder the family Picornaviridae. FMDV is a non-enveloped, single stranded, positive sense RNA genome, approximately 8,500 bases surrounded by four structural proteins (VP I - 4) to form an icosahedral capsid ${ }^{2}$. The virus has seven serotypes (A, O, C, Asia-1, SAT-1, SAT-2 and SAT3 ) and more than 65 subtypes of the seven serotypes. ${ }^{3}$ Foot and mouth disease is associated with high morbidity $(100 \%)$ and variable rate of mortality $(1-100 \%)$ depending on the age distribution of animals. In case of young animals, mortality rate may reach up to $100 \%$. It causes low productivity in the animal population of the affected countries by imposing severe restrictions through international trade on animal and animal products (meat, milk, hide and butter) due to its transboundary nature of transmission. ${ }^{4}$

FMD had been eradicated earlier by vaccination or by burning of affected animals from some developed countries like America,
Australia, Canada, England, and Japan but its appearance becomes a serious threat both for the domestic and wild animal population of these countries. ${ }^{5}$ Therefore, FMD is being considered as the most serious epizootic alarming disease in the world today. FMD is one of the major constraints for livestock development in Bangladesh too. Sero epidemiological investigation of this virus in cattle population indicated that four different types (A, O, C and Asia-1) of FMDV were prevalent in Bangladesh during 1960 to $1990 .{ }^{6}$ The recent study indicated that three different types (A, O and Asia-1) were prevalent in Bangladesh during 2007 to 2008 . $^{7}$

Inactivated foot-and-mouth disease (FMD) vaccines are currently used worldwide including Bangladesh. With the emergence of various FMD virus serotypes and subtypes, vaccines must become more suitable for field-based uses under the current circumstances in terms of the fast and proper selection of vaccine strains and vaccine improvement should be based on using attenuated virus strains with high levels of safety through adoptation of the virus in the cell line. ${ }^{8}$

Foot and mouth disease is generally characterized by the rapid appearance of high body temperature followed by formation of vesicles on the tongue epithelium and on the skin particularly on nose and inter-digital space of foot. ${ }^{9}$ The disease is often transmitted from the infected to the apparently healthy susceptible animal through air or direct contact. ${ }^{10,11}$ Usually, laboratory diagnosis is made by enzyme-linked immunosorbent assay (ELISA), complement fixation test (CFT), virus neutralization test (VNT) etc. for the detection of specific FMDV antigens from field samples. ${ }^{12,13}$

Control programs for FMD depend upon the background history of the disease, the ability of the affected countries to fund the disease control program, the availability of technical expertise, the geography 
of the region/country, and the application of legislation for animal health. There are many different techniques used for the control and eradication of FMD around the world. The initial step for effective control is early detection of disease (timely information on the FMD type) followed by laboratory confirmation. ${ }^{14}$ Member countries of the World Animal Health Organization can be divided into two groups on the basis of their FMD status; free countries and endemic countries. Use of a single vaccination program in an outbreak, without a booster dose, may not be sufficient to control an extensive outbreak as induced immunity may only last for four months. Even in a free country, it is very difficult to eradicate FMD after introducing a new infection because the virus can persist in the environment, fomites and reservoirs. ${ }^{15}$ Among the Southeast Asian countries, Indonesia, Brunei and Singapore are free of FMD. ${ }^{4}$ In the remaining countries, some parts of the Philippines and Malaysia have FMD free regions whereas the other countries, like Cambodia, Lao PDR, Myanmar, Vietnam, India, Pakistan, Nepal, Myanmar, Thailand, and Bangladesh are still infected with FMDV serotypes- O, A and Asia 1 and serotype- O has been a common serotype in infected countries in Southeast Asia including Bangladesh for many years.

Considering the above facts, the present research work has been undertaken to isolate, identify Foot and Mouth Disease virus (FMDV) directly from the field samples of recent outbreak areas of Mymensingh and to detect the types of the circulating FMDV by Antigen detecting ELISA and finally adaptation of isolated FMDV serotype(s) in BHK21 cell line for vaccine seed development.

\section{Materials and methods}

\section{Sample collection}

A total of 20 samples ( 15 tongue epithelia and 5 foot tissues) were collected from foot and-mouth disease suspected cattle (Figure 1A $\&$ 1B) during the outbreak of FMD from October to April 2012. The tissues were collected aseptically in special transportation medium for FMDV containing antibiotic-antimycotic and were put into ice carrier immediately after collection and transported to the laboratory.
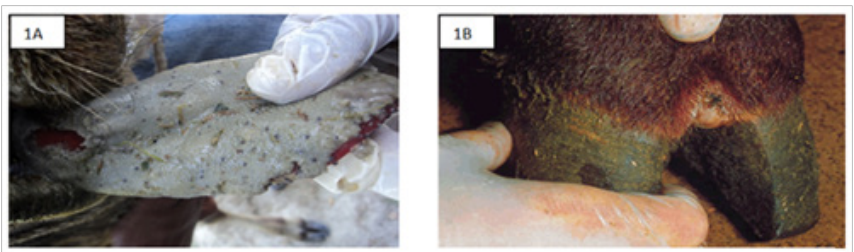

Figure I Collected tongue epithelia (IA) and foot tissues (IB) sample from foot and-mouth disease suspected cattle.

\section{Preparation of inoculum from field samples}

The field sample (tongue epithelium) was homogenized with mortar and pestle. Ten percent $(10 \%)$ suspensions were prepared by adding sterile phosphate buffered saline (PBS). The suspension was then centrifuged at $4000 \mathrm{rpm}$ for $15 \mathrm{~min}$ maintaining $4^{\circ} \mathrm{C}$ and supernatant was collected in $50 \mathrm{ml}$ falcon tube. The collected $10 \mathrm{ml}$ supernatant was treated with $1 \mathrm{ml}$ of antibiotic-antimycotic (100x), (Sigma, Germany) and was used as inoculum for serotyping by ELISA method and propagation into BHK-21 cell line.

\section{Sterility test of inoculums}

For sterility test, little amount of inoculums were inoculated into bacteriological media (BA) to identify the presence of any type of bacteria in the collected samples.
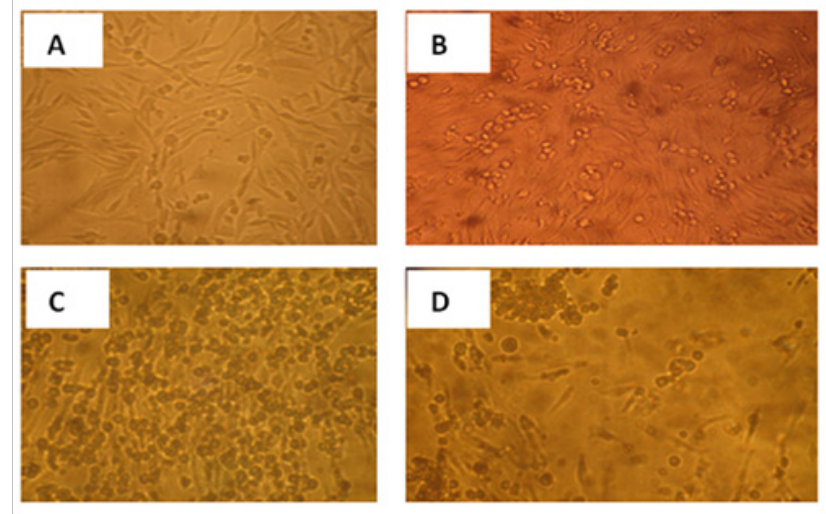

Figure 2 Normal BHK-2I cell line (A). FMD infected BHK-2I cell (stage $\mathrm{I}$ : initiation of infection and cell rounding started, photo taken after 12 hours,40x), (B).FMD infected BHK-2I cell (stage 2, almost 100\% cell infected, photo taken after 24 hours of infection,40x), (C).FMD infected BHK-2I cell (stage 3), (D).

\section{Subculture and adaptation of FMDV in BHK-2 I cell line}

BHK-21 cell line was kindly provided by Livestock Research Institute (LRI), Mohakhali, Dhaka. 70-80\% confluent growth of BHK-21 cell line bottle was washed with sterile PBS for 2-3times. After trypsinization the flask was left in the incubator for 5minutes. $10-20 \mathrm{ml}$ of the maintenance media was added in a $25 \mathrm{ml} \mathrm{flask.} 8 \mathrm{ml}$ of media containing cell was poured into another sterile cell culture bottle and returned to the incubator. The bottle was allowed to incubate at $37^{\circ} \mathrm{C}$ for 24 hours. The cells those formed complete and confluent monolayer's in the culture bottle within 24-72hours of distribution were selected for infection with viruses. The growth media from the bottle containing BHK-21 cell was removed and then the monolayer cells were washed with sterile PBS for 2times. The confluent monolayer was allowed to infect with $1 \mathrm{ml}$ of inoculum prepared from $10 \%$ suspension in PBS with field sample and the inoculum was spread over the cell sheet by tilting for about 45-60minutes for the establishment of better interaction. Then $5-10 \mathrm{ml}$ of the maintenance media was added in a $25 \mathrm{ml}$ flask (MEM supplemented with $2 \%$ fetal calf serum) and the vessel was returned to the incubator.Virus added bottle was allowed to incubate at $37^{\circ} \mathrm{C}$. The cells were examined twice daily under DIC microscope until show characteristic cytopathic effect (CPE) by FMDV.

\section{Isolation of FMDV from field samples through cell culture}

BHK-21 monolayer cell line sub culture was inoculated with the inoculums prepared from the tongue epithelia and foot tissues collected from the FMD suspected cattle. Presence or absence of virus replication in the cell culture that was subjected to infection with each of the field samples was detected by the development of various kinds of characteristic changes CPE (cell rounding, swelling, ICIB, giant cell) on to them. Infectious fluids (IF) containing FMDV were harvested after 48 to $72 \mathrm{hrs}$ of post infection and kept at $-20^{\circ} \mathrm{C}$ until further use.

\section{Serotyping by ELISA}

Serotyping of tested sample by ELISA was done according to manufacturer's instructions (PrioCHECK®FMDV type specific 
products) using ELISA plate (NUNC Immunoplate 1, Maxisorp (Gibco, Cat. \#4-39454A or Cat. \#4-42404), flat bottom, 96 well microplates and the reading was taken by touch screen ELISA reader (MR-96A, Mindray).

\section{Interpretation of results}

Colour development (from very strong to very weak) resulting from the five-fold dilution series of each of the control inactivated antigens

Table I Results of virus isolation from field samples in BHK-2I cell line was checked on plate 1 , rows $A$ to $H$ columns 1 to 4 to indicate that the plates had been correctly coated with antisera and that the test was valid. The mean background reactions were calculated for each plate by adding the optical density (OD) values of 5 and 6 wells of each row (serotype) and dividing by 2 - these OD values were due to the reagents and not to a specific reaction between antigen and antisera. Each mean background OD was subtracted for each serotype from the actual OD for that serotype to obtain a corrected OD value.
Place of Sampling

Gouripur Upazila of Mymensingh District, Bangladesh

$\begin{array}{ll}\text { Type and No. of Samples } \\ \text { TE } & \text { FT } \\ \text { I5 } & 5\end{array}$

\section{Positivity to FMDV}

TE $\quad$ FT Total

No. $\%$ No. \% No. \%

Legend, $\mathrm{TE}=$ Tongue epithelia; $\mathrm{FT}=$ Foot tissue

Table 2 Summary of foot and mouth disease virus serotypes detected by ELISA

\begin{tabular}{lllll}
\hline Sample Types & Sample no. & Serotypes & & \\
\hline Tongue Epithelia & 6 & A & O & Asia-I \\
Foot Tissue & 2 & 0 & 6 & 0 \\
Total & 8 & 0 & 2 & 0 \\
\hline
\end{tabular}

\section{Results and Discussion}

\section{Sterility test of inoculum}

All the field samples were processed and $1 \mathrm{ml}$ antibiotic-antimycotic solution 100X (Sigma, Germany) was added with appropriate amount to destroy bacterial and fungal contaminants. For sterility test, little amount was inoculated into bacteriological media (BA) to identify the presence of any type of bacteria in the collected samples. No bacterial growth was found in blood agar (BA) media which proved the samples were sterile.

\section{Virus isolation, adaptation of FMDV and their effects on BHK-2I cell line}

The research work was undertaken for isolation, identification, adaptation of FMDV in BHK-21 cell line and serotyping of FMDV. To conduct the research, 20 samples(tongue epithelia and foot tissues) were collected from the FMD suspected cattle of GouripurUpazila of Mymensinghdistricts. All the 20 samples were inoculated into BHK-21 cell line for the isolation of viruses. Of the 20 samples, 15 (75\%) samples were found positive for FMDVin cell culture. The cytopathic effect produced by the most field isolates of FMDV in BHK-21 cellswere manifested by the rounding and flattening of the cells, multinucleated giant cells formation, breaking down of the intracellular bridges and finally cell death which are characteristic findings of FMDV infected cells (Figure 2). Morphology of uninfected control BHK-21 cells was compared with the FMD infected BHK21 cells are shown (Figure 2). The finding of cell culture following infection with FMDV was correlated with the findings of Islam et al., ${ }^{16}$

Among the two types of field samples, the highest rate of isolation of FMDV in BHK-21 cell line was $86.67 \%$ from tongue epithelia which can be compared with the findings of Islam et al., ${ }^{15}$ who recorded $51.43 \%$ positive of tongue epithelia samples whereas the samples of foot tissue revealed only $40 \%$ positive (Table 1 ). This variation may be due to the site of sample collection, season of the year and system of collection. On the basis of present study, tongue epithelia and foot tissue appeared to be the first and second category samples respectively for isolation of FMDV.

\section{Serotyping by ELISA}

Total 8 samples in number were subjected for serotyping by ELISA. Colour development (from very strong to very weak) resulting from the five-fold dilution series of each of the control inactivated antigens was checked indicate that the plates had been correctly coated with antisera and that the test was valid. After observation of color development , FMDV serotype $\mathrm{O}$ was identified from all tested field samples (Table 2).

According to result of serotyping of FMDV by ELISA, it is concluded that the serotype of the collected samples from the Gouripur Upazila of Mymensingh was serotype "O". This record has a close agreement with the study of Islam et al., ${ }^{15}$ who reported that serotype $\mathrm{O}$ and $\mathrm{A}$ of FMDV were circulating in different areas of Bangladesh. Moreover, Chowdhury et al., ${ }^{6}$ also performed sero-epidemiological investigations and found that four different types (sero-types A, O, C and Asia-1) were prevalent in Bangladesh.

To know exactly, the prevailing serotype of FMDV in a population of animals, a large number of samples should be collected from different species of cloven hoofed animals (cattle, sheep, goat and buffalos) from several outbreaks areas of Bangladesh. The field samples should be analyzed regularly by the samples of year round outbreak areas of Bangladesh.Molecular characterization of FMDVwould also be appropriate. Finally from the present studies, it is clearly indicated that the samples of tongue epithelia were more positive than that of foot tissue in case of Foot and Mouth Disease (FMD) and the serotype of the suspected cases were serotype "O".

\section{Conclusion}

From this study it was revealed that Tongue epithelia were the best category sample for isolation and identification of FMDV. All the isolated serotypes of FMDV of Gouripur Upazila of Mymensingh were found serotype "O" during this study. The ELISA technique followed by BHK-21 cell adaptation of virus is very sensitive method 
of FMDV isolation and identification and can be used for the detection of FMD virus serotype. In future, the research findings may be used for the preparation of vaccine against FMDV that will have future application in the national FMD control program.

\section{Acknowledgements}

The authors are grateful to Livestock Research Institute (LRI), Mohakhali, Dhaka, Bangladesh for providing the BHK-21 cells to conduct this work.

\section{Conflicts of interest}

Author declares there are no conflicts of interest.

\section{Funding}

None.

\section{References}

1. Fenner FJ, Gibbs PJ, Murphy FA, et al. Virus interacting layered phyllosilicates and methods of inactivating virus on animate and inanimate surfaces. Vet Virol. 1993. p.403-430.

2. Rueckert RR. Picornaviridae: the virus and their replication. In: Fields BN, et al. (Eds.), Fields Virology, (3rd edn), Lippincott-Raven Publishers, Philadelphia, USA. 1996. p.609-654.

3. Bachrach HL. Foot and mouth disease. Ann Rev Microbiol. 1968;22:201-244

4. OIE. Principles of Veterinary Vaccine Production. OIE Terrestrial. 2004 p. $1-15$.

5. David A. More culls planned as Britain wrestles with foot and mouth. Nature. 2001;410(6827):395-498.

6. Chowdhury S, Rahman MZH, Rahman MF, et al. Strains of footand-mouth disease virus in different districts of Bangladesh. AJAS. 1996;9(3):315-317.
7. Zinnah. Development of molecular methods for simultaneous detection of foot-and-mouth disease viruses serotypes prevalent in Bangladesh. Mymensingh, Bangladesh. 2008.

8. Park JH. Requirements for improved vaccines against foot-and-mouth disease epidemics. Clin Exp Vaccine Res. 2013;2(1):8-18.

9. Sahan MS. The virus of foot-and-mouth disease. Ann NY Acad Sci. $1962 ; 101: 444-454$

10. Domingo E, Mateu MG, Martinez MA, et al. Genetic variability and antigen diversity of foot and mouth disease virus. Appl Virol Res. 1990;2:233-266.

11. Gomes L, Rahmalho AK, de Mello PA. Infectivity assay of foot and mouth disease virus: contact transmission between cattle and buffalo (Bubalasbubalis)in the early stage of infection. Vet Rec. 1997;140(2):43-47.

12. Ferris NP, Powell H, Donaldson AL. Use of pre-coated immunoplates and freeze-dried reagents for the diagnosis of foot-and mouth disease and swine vesicular disease by enzyme-linked immunosorbent assay (ELISA). J Virol Methods. 1988;19(3-4):197-206.

13. Hamblin C, Armstrong RM, Hedger RS. A rapid enzyme-linked immunosorbent assay for the detection of foot-and-mouth disease virus in epithelial tissues. Vet Microbiol. 1984;9(5):435-443.

14. Fernandez J, Aguero M, Romero L, et al. Rapid and differential diagnosis of foot-and-mouth disease, swine vesicular disease, and vesicular stomatitis by a new multiplex RT-PCR assay. $J$ Virol Methods. 2008;147(2): 301-311.

15. Joo YS, An SH, Kim OK, et al. Foot-and-mouth disease eradication efforts in the Republic of Korea. Canad J Vet Res . 2002;66(2):122-124.

16. Islam MA, Rahman MM, Adam KH, et al. Epidemiological implications of the molecular characterization of foot-and mouth disease virus isolated between 1996and 2000 in Bangladesh. Virus Genes. 2000;23(2):203-213. 